\title{
Experience of a Co-creation Workshop with elderly people using natural semantic networks
} \author{
Javiera Ortega Bastidas ${ }^{4}$, Cristhian Pérez Villalobos ${ }^{4}$ \\ ${ }^{1}$ Universidad Técnica Federico Santa Maria \\ juancarlos.briede@usm.cl \\ ${ }^{2}$ Universidad del Bío-Bio \\ ileal@ubiobio.cl \\ ${ }^{3}$ Universidad de Valparaiso \\ rodrigo.vargas@uv.cl \\ ${ }^{4}$ Universidad de Concepción \\ javieraortega@udec.cl \\ cperezv@udec.cl
}

Juan Carlos Briede Westermeyer ${ }^{1}$, Isabel Leal Figueroa ${ }^{2}$, Rodrigo Vargas Callegari ${ }^{3}$,

\begin{abstract}
The core idea of design is being able to improve the quality of people's lives. This is a commendable purpose, that gives a deep sense of transcendence to the profession that deals with the daily experiences of human beings. This intention is inexorably transformed during the design process, as paying attention to the experiences of others requires putting yourself in their shoes. This attention process requires recognizing the particular context of users, as is the case of the elderly who will be the target population of this research. The issues associated to the Elderly are diverse and complex; hence, it is necessary to focus a reflection from different disciplines that allow actively integrating the users in this context. Co-creation is a participative model in design that allows addressing a challenge integrated by different specialists, both for the exploration of problems and of the associated opportunities, analyzing them from their diffuse and incomplete state, until their clear and effective profiling. This generative research method actively includes the users in said project. Considering the nature of co-participative design, the goal of this study was to characterize the perception of each participant in a Cocreation Workshop, whose core subject was the elderly. The co-creation workshop considered an active participation of professionals and elderly users. A qualitative methodology was used to evaluate the perception of participation, with a descriptive and comparative observational design. The data collection tool was natural semantic networks. Starting from this, the concepts and notions of the participants were systematized regarding the relevant issues within these cocreation processes. The article presents a notion map revealed by the participants of a cocreation workshop. Said terms were associated to each one of the activities or constructs identified within the co-creation workshop. Six natural semantic network sections were designed, corresponding to the co-participative Design Workshop: (1) My contribution; (2) My communication; (3) Teamwork; (4) What I learned; (5) Modeling; (6) Old age.
\end{abstract}




\section{Introduction}

The core idea of design is based on the assumption that its products should improve the people's quality of life. This requires deploying a series of attentional processes that will allow the designer to systematize the complexity of the data collected, considering multidimensional factors. In other words, this systematization is not only focused on technological challenges associated to optimizing manufacturing, but also the possibility of identifying problems and opportunities in real contexts and considering social interactions. The new design methodologies have discussed the importance of paying attention to the users' problems from diverse professional and personal perspectives. This assumes the use of User Centered Design, that is to say, it requires placing the human being at the center or core of the process itself. Participative actions allow considering the user information and actively integrating this within the design process, in a co-creation process with design specialists. The open question in this regard is: How do the different participants perceive a co-creation experience?

Many co-creation workshops focus on the process (interaction) and results (ideas and reflections), considering the perception of the participant's experience through interviews and spatially through focus groups, which allow collecting a large amount of data relatively quickly and at a low cost (Wilkinson, 2004). In this sense, the application of semantic networks would allow making exploratory analysis to guide the qualitative analysis reflection process, for example, determining more clearly some questions for an interview script or a focus group with the workshop's participants. At the same time, it would allow quickly identifying certain general patterns regarding participant notions and, from this, be able to go into greater depth on critical aspects or those of interest.

The experience that is documented in this study focuses on the context of the elderly. The highly relevant subject of aging has been adopted, aiming at answering the social complexities that can be addressed by the design, as between 2000 and 2050 the proportion of inhabitants around the world over 60 will double, passing from $11 \%$ to $22 \%$. In absolute numbers, this age group will rise from 605 million to 2 billion over half a century. In other words, the number of people of 80 and above will increase almost fourfold, to 395 million (Martínez,2020). Therefore, aging constitutes one of the greatest challenges that society must face in the coming years and it stands out among the topics that design must address nowadays. This demographic change has been established as an economic impact phenomenon in public policies and the development of communities and families, being projected as one of the most important social transformations of our time, aging (CEPAL,2017) motivated, at the same time, by the increased life expectancy and reduction of birth rates (Mora \& Herrera, 2018), apart from becoming a global challenge, today said population is one of the main health concerns (Bayarre, 2017), along with mental health, infectious diseases, chronic diseases and, ultimately, comprehensive medical attention. The issue of aging is focused on aspects associated to resources, specialists and health insurance (CEPAL,2017). Complex issues that must be faced in an interdisciplinary way, seeking to design products and services that satisfy the demands and cultural differences along with the biopsychosocial changes within this population segment ((Briede et al.,2017a).

Considering this context of interest, a co-creation workshop was held where elderly people, preadolescents, industrial design professionals, businesspeople, physicians, psychologists, physiotherapists, and other health professionals took part. The workshop lasted a week, with three sessions, where co-creation methods were taught, the problem outlined and prototypes 
created through Challenge Based Learning (Briede-Westermeyer et al.,2017b), before finishing with the definition of future opportunity areas. Now, considering the particular context of the elderly, it is essential to think about design evaluation methodologies that allow a short descriptive participation. For this, it is necessary to go back to the Semantic Association Memory theory, whose goal is gathering the most original and primary senses regarding an experience (Figueroa et al, 1981). The contribution of this kind of evaluation is not just theoretical, but also practical. Its theoretical contribution allows finding out how the participants of a co-creation workshop perceive the experience of the integration of perspectives when facing a design issue. The practical value of this proposal is that the entire deployment of co-creation becomes an opportunity. At the Fuzzy-Front End (FFE) (Herstatt \& Verworn, 2004), an experience of this nature constitutes the opportunity where the product strategy is formulated, opportunities are identified and chosen, ideas are generated, evaluated and chosen, and the concept is developed and finally is tested (Stevanović et al.,2016). This provides the possibility to explore areas and contexts with users and stakeholders early on to study opportunities. In this sense, co-creation is a suitable methodological approach for this phase, as it allows having a collective act of creation which is experienced jointly by two or more people and where the intention is creating something new that was previously unknown; without knowing if the deliverable is going to be a product, a service or another proposal (Sanders \& Simons, 2009), with the goal of approaching the future users who this will be designed for (Sanders \& Stappers, 2008).

Having said this, the purpose of this study is to reveal experiences associated to the participation in said workshop, with emphasis on the notions associated to subprocesses or activities within the Co-creation process. Specifically, it intends on characterizing the perception of each participant in a Co-creation Workshop, whose core issue was to address the challenges and issues of the elderly by addressing their daily activities.

\section{Methodology}

A qualitative methodology was used, with a descriptive and comparative observational design to evaluate the perception of each participant in a Co-creation Workshop, whose core issue was the elderly. 19 people took part in the Co-creation Workshop. From all the participants, 58\% $(n=11)$ were aged between 24 and 34; 11\% $(n=2)$ between 34 and 44; 16\% $(n=3)$ between 44 and $54 ; 11 \%(n=2)$ between 54 and 64 and just $1 \%(n=1)$ between 64 and $75.68 .4 \%(n=13)$ of the professionals who took part in the workshop had previously worked with the elderly. Most of them came from the healthcare area: physiotherapists, nurses, psychologists and physicians $(\mathrm{n}=8,42.1 \%)$, and from the design area, specifically, industrial designers and/or application developers $(\mathrm{n}=8), 42.1 \%) .10 .5 \%(\mathrm{n}=2)$ of the professionals came from the IT engineering and bioengineering area and just $5.2 \%(\mathrm{n}=1)$ were professors. The participants were chosen through a non-probabilistic quota sampling, so that they represented different profiles: old people, preelderly, industrial designers, businesspeople and healthcare professionals.

I. Instrument Design

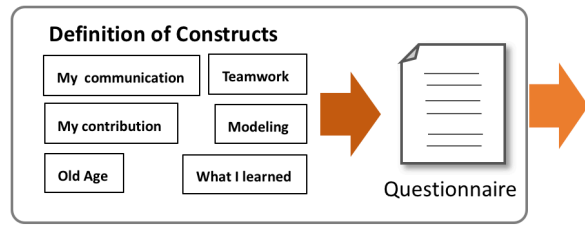

II. Application

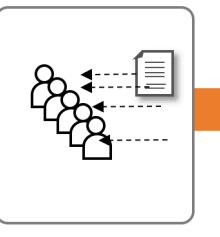

III. Results Analysis

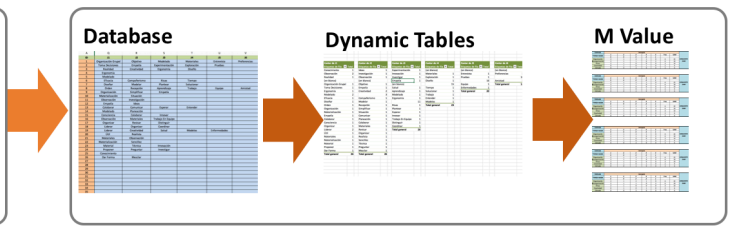


Figure 1. Methodological approach

\section{Description of the workshop and context:}

The workshop involved the participation of industrial designers, entrepreneurs, healthcare professionals and elderly people. Three sessions were held. The first two to choose the problem and prepare the co-creation activity, and the third to hold the co-creation activity together with the elderly.

Session 1 (interdisciplinary groups): Whose purpose was to get to know each other and share results from the previous task ${ }^{1}$, selecting a specific issue for the elderly and a thematic context. Session 2 (interdisciplinary groups): In order to develop the work guidelines and supporting material (models, posters, parts, and pieces).

Session 3 (interdisciplinary groups + elderly people): A co-creation session of each group took place, and results, experiences and future challenges were shared, with the purpose of presenting the subject and issue of each group, where each elderly person decided which group to work with. The themes worked on can be seen in Table 1 .

Table 1. Themes and solutions developed in the co-creation workshop

\begin{tabular}{|l|l|}
\hline \multicolumn{1}{|c|}{ Subject } & \multicolumn{1}{|c|}{ Solution } \\
\hline Safe bathroom & Anti-slip bathtub and bathroom \\
\hline Ideal Kitchen & $\begin{array}{l}\text { Ultralight dishes/adjustable furniture/ identifiable knife / can opener } \\
\text { adapted to the lid. }\end{array}$ \\
\hline Sarcopenia & Physiotherapy gym for the bed \\
\hline $\begin{array}{l}\text { Access to social benefit } \\
\text { information }\end{array}$ & Radio station \\
\hline $\begin{array}{l}\text { Access and identification } \\
\text { of public restrooms }\end{array}$ & $\begin{array}{l}\text { System of maps and geolocalization and centers with disabled } \\
\text { restrooms/private restrooms with rest areas/geolocalization } \\
\text { lens/identifiable islands and meeting spaces }\end{array}$ \\
\hline
\end{tabular}

Finally, with the goal of getting to know the notions regarding key and essential issues within the activities run in the Workshop, the decision was made to "explore" the application of natural semantic networks in this study. The work was done in groups which at least had a member to represent each profile. At the end of the practical course, participants answered a questionnaire where they could share their experiences about 6 categories that the researchers had defined beforehand. These categories emerge from the results which have been identified throughout the research process (Briede-Westermeyer et al., 2019).

The tool used was designed from the natural semantic networks technique. Six natural semantic network sectors were designed corresponding the co-participation Design Workshop, with a key concept at the beginning:

(1) My contribution: The personal contribution both to the team and to the context of the development of the assignment.

(2) My communication: Referring to the capacity and effectiveness to be able to communicate with the team members

(3) Teamwork: Experience related with being able to interact, analyze, agree and articulate the work as a group

\footnotetext{
${ }^{1}$ Every participant had to interview an elderly person and ask them questions about which of the products they liked and hated most.
} 
(4) What I learned: Which contents, knowledge and experience I was capable of examining after having participated in this workshop

(5) Modeling: The capacity to project, design and setup characteristics and attributes of the solution, either conceptually or physically.

(6) Old age: What does it mean or imply to be part of this age group? Meaning, implications, challenges and difficulties.

Each one of these predefined categories comprised two sections, where they had to indicate the descriptors that they felt were most associated to the core concept of each network: (a) First, they had to define the concept listing verbs, adverbs, adjectives, nouns, names or pronouns, without using articles or prepositions; (b) Second, the participants had to rank the level of relevance of each defining word that they indicated in the previous section. A descriptive table was designed from this data which included the most relevant defining words mentioned by the participants. Then, the main values of the semantic network were calculated, using the proposal of Figueroa, González \& Solis (1981) and Valdez (1998).

The values considered in each semantic network were the following (Valdez, 1998, p.69):

(a) J Value, represents all the defining words mentioned by the participants. This lets us obtain a semantic wealth indicator of the network, identifying that, the higher the number of words, the greater the wealth. This value is obtained by adding together all the defining words given by the participating subjects;

(b) M Value: is related to the hierarchy through which each word defined by the subjects has a greater semantic weight. To obtain this value, the frequency of appearance of the defining works must be multiplied by the ranking assigned to each one of these. The set of $\mathrm{M}$ values will be called the SAM (Semantic Association Memory) set and form the core of the semantic network, in other words, the core of meanings that the concept will have. It tends to be formed by the ten defining words that have the highest $\mathrm{M}$ value of the network that emerge in the data collection process. The SAM set can be the basis for later intra and inter-group correlations and comparisons (Figueroa et al., 1981). However, for this study these were only used to make an exploratory description;

(c) FMG Value: this refers to the semantic distance there is between different defining words within the SAM set. The analysis is made from the rule-of-three, taking the defining word with the highest $\mathrm{M}$ value, which represents $100 \%$ in terms of percentage, as the starting point. For each defining word, its $\mathrm{M}$ value will be calculated by multiplying it by 100 and dividing it by the higher M value of the network being analyzed (Valdez, 1998, p.70).

The results obtained from this data allow identifying and characterizing the semantic senses the subjects attribute to the experience. This means to say that the semantic network technique is an exploratory technique and allows researchers to have a first approach to the meanings of the subjects.

\section{Results}

Regarding the "My contribution" semantic network, it is possible to see a total $\mathrm{J}^{2}$ Value of 159. Within this, we can recognize 6 defining words which appear most often ${ }^{3}$ : "creativity"

\footnotetext{
${ }^{2}$ The $\mathrm{J}$ value represents all the defining words mentioned by the participating subjects. This lets us obtain a semantic wealth indicator of the network, identifying that the higher the number of words, the greater its wealth is. This value is obtained by adding together all the defining words that were attributed by the participating subjects (Valdez, 1998, p.69).

${ }^{3}$ The $\mathrm{M}$ value is related to the ranking that each defining word is given to by the subjects has a higher semantic weight. To obtain this value, the frequency of appearance of the defining words must be multiplied by the ranking
} 
(SAM=41), followed by "ideas" (SAM=31), then "construction" (SAM=22). Words like "leadership" (SAM=18), "responsibility" $(\mathrm{SAM}=14)$ and companionship" $(\mathrm{SAM}=13)$ come next. In Table 1 we can see the detail by frequency and the semantic distance value there is between the different defining words (FMG). This allows seeing that the word, "creativity", apart from its frequency, represents an FMG value of $100 \%(n=10)$, followed by the word, "ideas", with an $\mathrm{FMG}^{4}$ of $75.6 \%(\mathrm{n}=6)$.

Table 1. Description of the semantic network corresponding to "My Contribution"

\begin{tabular}{lllll}
\hline & & $\mathrm{M}$ & FREC & FMG \\
\hline 1. & Creativity & 41 & 10 & $100 \%$ \\
2. Ideas & 31 & 6 & $75.6 \%$ \\
3. Construction & 22 & 5 & $53.6 \%$ \\
4. Leadership & 18 & 3 & $43.9 \%$ \\
5. Responsibility & 14 & 3 & $34.1 \%$ \\
6. Companionship & 13 & 3 & $31.7 \%$ \\
\hline
\end{tabular}

With regard to the semantic network "My communication", this has a total J value of 159 . The semantic core comprised the word "effective" (SAM=29), followed by "fluency" $(\mathrm{SAM}=10)$, "concise" (SAM?14), "seriousness" (SAM=9) and, finally, "assertive" (SAM=8). As for to the detail by frequency and the semantic distance value there is between the different defining words (FMG), we can see that an important weight is given to the concept of "effectiveness".

Table 2. Description of the semantic network corresponding to "My communication"

\begin{tabular}{lllll}
\hline & & $\mathrm{M}$ & FREC & FMG \\
\hline 1. & Effective & 29 & 7 & $100 \%$ \\
2. & Fluency & 10 & 2 & $34.4 \%$ \\
3. & Concise & 14 & 3 & $48.2 \%$ \\
4. Seriousness & 9 & 2 & $31.0 \%$ \\
5. & Assertive & 8 & 2 & $27.5 \%$ \\
\hline
\end{tabular}

The semantic network "teamwork" was examined third. It had a total J value of 91. The semantic core comprised the word "organization" (SAM=22), followed by "disorganization" $(\mathrm{SAM}=19)$, "effective" (SAM=14), "creativity" (SAM=6) and finally, "comfortable" $(\mathrm{SAM}=6)$. Regarding the detail about the frequency and the semantic distance value there is between the different defining words (FMG), we can see that an important weight is attributed in this to the concept of "organization" (See table 3).

assigned to each one of them. The set of M values will be called SAM (Semantic Association Memory) set and it constitutes the core of the semantic network, that is to say, the core of meanings that the concept will have (Figueroa et al., 1981)

${ }^{4}$ The FMG value refers to the semantic distance there is between the different defining words in the SAM set (Váldez, 1998, p.70). 
Table 3. Description of the semantic network corresponding to "Teamwork"

\begin{tabular}{lllll}
\hline & & $\mathrm{M}$ & FREC & FMG \\
\hline 1. & Organization & 22 & 6 & $100 \%$ \\
2. Disorganization & 19 & 6 & $86.3 \%$ \\
3. Effective & 14 & 3 & $63.6 \%$ \\
4. Creativity & 6 & 2 & $27.2 \%$ \\
5. Comfortable & 6 & 2 & $27.2 \%$ \\
\hline
\end{tabular}

In the distribution of the words regarding their M scores, the word "organization", has an important role for the participants, sitting in a similar position to the word "disorganization". Both seem to have a privileged operation in the notion that is attached to Teamwork. The semantic network "What I learned" was examined fourth. This had a total J value of 133. The semantic core is comprised by the word "modeling" (SAM=19), followed by "observation" $(\mathrm{SAM}=14)$, "to lead" $(\mathrm{SAM}=10)$, "creativity" $(\mathrm{SAM}=8)$ and finally, "empathy" $(\mathrm{SAM}=12)$. Regarding the detail by frequency and semantic distance value there is between the different defining words (FMG), we can see that an important weight is attributed to the concept of "modeling" (See table 4).

Table 4. Description of the semantic network corresponding to "What I learned"

\begin{tabular}{rllll}
\hline & & $\mathrm{M}$ & FREC & FMG \\
\hline 1. & Modeling & 19 & 5 & $100 \%$ \\
2. & Observation & 14 & 3 & $73.6 \%$ \\
3. & To lead & 10 & 2 & $52.6 \%$ \\
4. & Empathy & 12 & 3 & $63.1 \%$ \\
5. & Creativity & 8 & 2 & $42.1 \%$ \\
\hline
\end{tabular}

We can see the detail of the semantic distance that occurs between the word "modeling" and the rest of the network set. The semantic distance is abrupt, which places modeling as an essential element in the workshop experience.

After this, the "Modeling" semantic network was analyzed, presenting a total J value of 76 . The semantic core was comprised by the word "useful" (SAM=11), followed by " "effective" $(\mathrm{SAM}=10)$, "moldable" (SAM=10), "flexible" $(\mathrm{SAM}=3)$ and, finally "planned" $(\mathrm{SAM}=6)$. As for the detail by frequency and the semantic distance value there is between the different defining words (FMG), we can see that an important weight is attributed to the concept of "modeling” (See table 5).

Table 5. Description of the semantic network corresponding to "Modeling"

M $\quad$ FREC $\quad$ FMG




\begin{tabular}{lllll}
\hline 1. & Useful & 11 & 3 & $100 \%$ \\
2. & Effective & 10 & 3 & $90.9 \%$ \\
3. & Moldable & 10 & 3 & $90.9 \%$ \\
4. & Flexible & 3 & 2 & $27.2 \%$ \\
5. & Planned & 6 & 2 & $54.5 \%$ \\
\hline
\end{tabular}

The semantic distance that occurs between the word "useful" shows that this close the words "effective" and "moldable", before strongly distancing itself from the word "flexible".

After that, the semantic network "Old Age" had a total J value of 76. The semantic core was comprised by the word "deterioration" (SAM=13), followed by "problems" (SAM=8), "slowness" (SAM=12), "loneliness" (SAM=5) and, finally, "wishes" (SAM=6). As for the detail about frequency and the semantic distance value there is between the different defining words (FMG), we can see that an important weight is attributed to the concept of "deterioration" (See table 6).

Table 6. Description of the semantic network correspond to "Old Age"

\begin{tabular}{lllll}
\hline & & $\mathrm{M}$ & FREC & FMG \\
\hline 1. & Deterioration & 13 & 3 & $100 \%$ \\
2. & Problems & 8 & 3 & $61.5 \%$ \\
3. Slowness & 12 & 3 & $92.3 \%$ \\
4. Wishes & 6 & 2 & $46.1 \%$ \\
5. Loneliness & 5 & 2 & $38.4 \%$ \\
\hline
\end{tabular}

The detail of the semantic distance that occurs between the word "deterioration" is that this is close to the word "slowness" and distances itself from the words "problems" and "wishes". Finally, and using the word cloud techniques (figure 1), each construct related to the Cocreation activity run is represented, letting us quickly display certain patterns (McNaught \& Lam , 2010). This allows revealing these notions and analyzing them in regard to the consensus process during the workshop, to face not only the problems that elderly people face on a daily basis, but also how these notions regarding Old Age build a stereotype, based on negative aspects. 


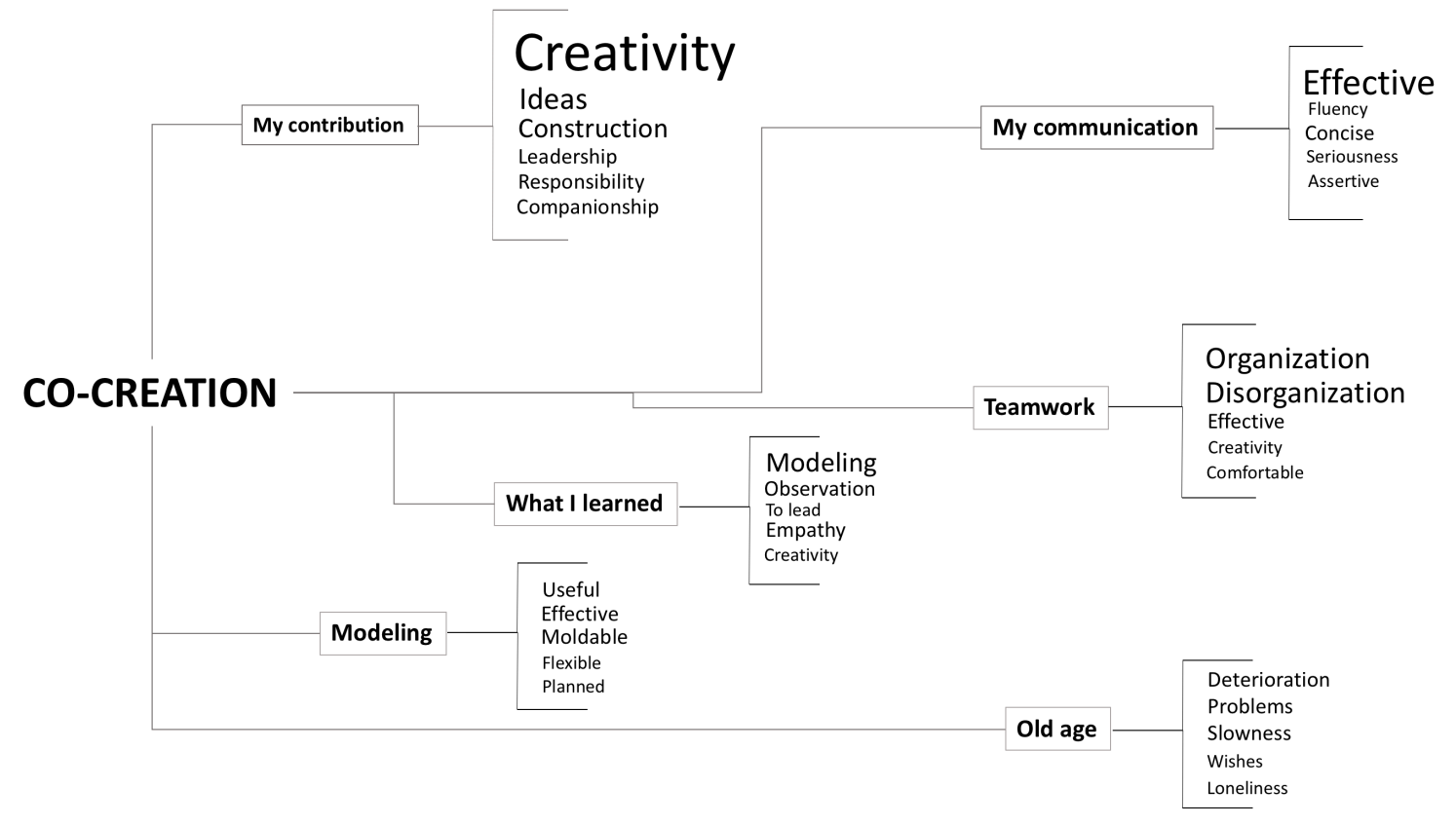

Figure 1. Word cloud of the notions associated to the co-creation experience with the Elderly.

\section{Discussion of the results}

The goal of the results obtained in this project is being an initial approach to those most original senses of an experience. They do not have a goal of consciously going into depth in said sense; on the contrary, the value of the results is that it lets us have a global idea about what co-creation means for the subjects. From the 3 criteria that are presented to the subject in first person (My Contribution, My Communication and What I learned), the first two are of a positive quality ("I am creative", "I am effective"), and the third is practical-value based ("I learned to model"). Likewise, we can see how teamwork also had a positive appreciation around the idea that must be organized. Modeling, for its part, is presented as a value of the learning process. In such a scenario, it is expected that there will be three positive options: it is useful, effective, and moldable. It is curious that from all these concepts (except disorganized), only the criteria Old Age brings together three negative concepts ("deterioration", "slowness" and "problems"), and only one positive or neutral one ("wishes"), which is why it is evident that $100 \%$ obtain a negative value, "deterioration", followed by "slowness", both on a lower social estimation scale than problems and wishes. If we transfer the semantic answers (offered by the network) to discourse, it could read as follows: "I am not old, I took part in the Co-creation Workshop, contributing with my creativity, communicating effectively and working in a team in an organized manner. I learned how to model, which is useful, effective and moldable for elderly people with deterioration and slowness". This discourse, reflects maintaining and possible reinforcing prejudice about old age, especially because the elderly participants were independent, many of them quite active in their community, even leaders within it, creative, balanced and lucid people, in terms of what they expected. They were communicatively competent and dynamic in their participation. As such, it is worth asking: why did negative aspects associated to age dominate, if what was expected was greater empathy and recognition? Why does procedural learning (very suitable to design) prevail over attitudinal or conceptual ("what I learned") learning? Do Co-creation and Co-design encourage dialog and empathy? Is this semantic network reflected in the Design result? These are some of the questions that we 
leave unanswered, as they need an active reflection regarding the co-creation method in the particular context of Old Age.

\section{Conclusion}

Using the results obtained by the semantic network, it can be seen that there is some bias attached to the elderly. This bias may be conditioned by the socio-cultural context; however, to be clear about this, it is necessary to look at this aspect in greater depth in future studies. The contribution of the semantic network definitively allows making out a certain perception of bias, but at the same time, it allows identifying a certain kind of positive valuation and collaboration regarding the elderly. This means to say that the co-creation experience could be operating under certain dimensionalities of valuation and rejection with the user. Although cocreation represents an important paradigm for designers, we would have to ask ourselves the following questions: are designers prepared for the co-creation experience? Which habits would have to be recorded in the designer's tradition? These questions would help us look further into whether there is a trend, or something similar, for preferring a unilateral design practice. If this is so, these results may be affected by the disciplinary tradition. In this sense, the application of semantic networks allows mapping notions of the meanings that participants have about an issue or aspect and the value assigned through these. The application as a tool within co-creation workshops in industrial projects and contexts with companies would allow generating thematic immersions and allow looking into the conceptual notions of products, services and experiences.

Following on from this, Co-creation Workshops do not necessarily convoke immediate and deep attitudinal changes in the participants. It is possible that for this to be produced, activities need to be included before the creative meeting along with later reflections. In this sense, these opportunities for induction and reflection may mean sensitizing and increasing the empathy of the act and of the products created, reducing the welfare-market paradigm where design is often present. Finally, we must highlight that the application of semantic networks as a tool to investigate notions, does not look to replace other qualitative methods, but rather to be able to map notions that emerge within a group of participants, and use them as a resource to develop upon and share these notions instilled in our mind along with the bias/conditioning that these can generate upon researching a theme from an interdisciplinary point of view. In this sense, the identification of language (terms and concepts) would be the basis to be able to go into greater depth through qualitative face-to-face interviews, using them as complements within the workshops themselves with the goal of contributing to a shared understanding of the problem and the context being addressed.

\section{Acknowledgement}

This work was funded by the CONICYT / FONDECYT 1171037 project.

\section{References}

Bayarre, H. D. (2017) Múltiples perspectivas para el análisis del envejecimiento demográfico. Una necesidad en el ámbito sanitario contemporáneo. Revista Cubana de Salud Pública, 43(2): 313-316. 
Briede-Westermeyer J.C, Pérez-Villalobos C., Bastías-Vega N., Bustamante-Durán C., Olivera-Morales P., Parra-Ponce P., Delgado-Rivera M., Cabello-Mora M., CamposCerda I., (2017) (b)Interdisciplinary experience for the design of health care products. Rev Med Chile, 145:1289-1299.

Briede-Westermeyer J.C, Pérez-Villalobos C., Ortega-Bastidas J., Leal- Figueroa I. (2018) Cocreation Workshop Oriented to the Autonomous Elderlies in Chile: Unveiling the Experience of the Participants. 1st International Conference on Human Systems Engineering and Design: Future Trends and Applications (IHSED 2018).

Briede-Westermeyer J.C., Leal-Figueroa I., Pérez-Villalobos C. (2017) (a) Designers, are they stars or facilitators of interdisciplinary work? The Co-creation and consensus in the design of products for elderly. Revista 180, No40: 20-29

Comisión Económica para América Latina y el Caribe (2017). Derechos de las personas mayores: retos para la interdependencia y autonomía (LC/CRE.4/3/Rev.1), Santiago, 2017.

Figueroa, J. G., González, E. y Solis, V. (1981). "Una aproximación al problema del significado: las redes semánticas”, en: Revista Latinoamericana de Psicología, 13 (3), 447-458.

Herstatt C., Verworn B. (2004) The 'Fuzzy Front End' of Innovation. In: Bringing Technology and Innovation into the Boardroom. Palgrave Macmillan, London

Martínez, R. Indice de envejecimiento de las Americas Available online: https://public.tableau.com/views/EnvSal IndiceEnvejecimiento viz1/Dashboard1?:em bed $=$ yes\&:toolbar $=$ yes\&:showVizHome $=$ no $($ accessed on 10 Mar 2020).

McNaught C., Lam P.(2010)Using Wordle as a Supplementary Research Tool. The Qualitative Report Volume 15 Number 3 May 2010 630-643 http://www.nova.edu/ssss/QR/QR153/monaught.pdf

Sanders L. \& Simons G. (2009) A Social Vision for Value Co-creation in Design. Technology Innovation Management Review. https://timreview.ca/article/310

Stevanović M., Marjanović D., Štorga M. (2016) Managing the process of preparation for product development - ideas assessment and evaluation. DS 84: Proceedings of the DESIGN 2016 14th International Design Conference, 2016, 1155-1164

Valdez J (1998) Las redes semánticas naturales: Usos y aplicaciones en Psicología Social. México: Universidad Autónoma de México. 55-80 pp.

Wilkinson S. (2004) CHAPTER FOURTEEN. Focus Groups. In Doing Social Psychology Research. Page 344. Eds. Glynis M. Breakwell. The British Psychological Society and Blackwell Publishing Ltd. 